\title{
The stability of rural outreach services: a national longitudinal study of specialist doctors
}

O utreach health care services by medical specialists, involving travel away from their normal practice to underserved areas, is a key strategy to promoting access to such services in rural Australia. Evidence shows that rural outreach clinics can improve access to specialist services, reducing hospitalisations ${ }^{1}$ and achieving similar clinical outcomes to metropolitanbased clinics. 2,3 The degree to which specialists continue to visit the same town over time is important to sustaining access and supporting follow-up care. About one in five Australian specialists provides rural outreach services, ${ }^{4}$ but we do not know how stable these services are.

The available evidence about the continuity of rural outreach services is scant, localised to individual services, and descriptive in nature. One small-scale qualitative evaluation has shown how service structure and design can influence outreach sustainability, but it was restricted to a remote setting. ${ }^{5}$ Case studies of successful ongoing outreach services by a selected range of specialist types in both rural and regional settings have been reported. ${ }^{1,6,7}$

A parliamentary enquiry that appraised outreach services in regional Australia suggested that outreach health care might better balance the social and professional needs of practitioners than their being permanently located in a rural area. ${ }^{8}$ In one survey, visiting specialists reported less negative effects of rural practice than did resident specialists. ' However, an evaluation of several demonstration outreach services of at least 5 years' duration indicated that diverse challenges can threaten ongoing service provision. In particular, the leadership of individual specialists was considered to play a strong part in sustaining outreach service delivery. ${ }^{6}$

Since 2000, the Australian government has provided subsidies for the

\section{Abstract}

Objective: To explore the characteristics of specialists who provide ongoing rural outreach services and whether the nature of their service patterns contributes to ongoing outreach.

Design, participants and setting: Specialist doctors providing rural outreach in a large longitudinal survey of Australian doctors in 2008 , together with new entrants to the survey in 2009, were followed up to 2011.

Main outcome measures: Providing outreach services to the same rural town for at least 3 years.

Results: Of 953 specialists who initially provided rural outreach services, follow-up data were available for 848 . Overall, 440 specialists (51.9\%) provided ongoing outreach services. Multivariate analysis found that participation was associated with being male (odds ratio [OR], 1.82; 95\% Cl, 1.28-2.60), in mid-career (45-64 years old; OR, 1.44; 95\% Cl, 1.04-1.99), and working in mixed, mainly private practice (OR, 1.73; 95\% Cl, 1.18-2.53). Specialists working only privately were less likely to provide ongoing outreach (OR 0.51; 95\% Cl, 0.32-0.82), whereas metropolitan and ruralbased specialists were equally likely to do so. Separate univariate analysis showed travelling further to remote towns had no effect on ongoing service provision. Outreach to smaller towns was associated with improved stability.

Conclusions: Around half of specialists providing rural outreach services continue to visit the same town on an ongoing basis. More targeted outreach service strategies should account for career stage and practice conditions to help sustain access. Financial incentives may increase ongoing service provision by specialists only working privately. There is some indication that outreach services delivered to smaller communities are more stable.

costs of rural outreach work, most recently through the Rural Health Outreach Fund (RHOF). ${ }^{10}$ However, to effectively target the RHOF, more information is needed about the determinants of ongoing practice.

The factors influencing ongoing outreach service provision by specialists are yet to be established. The aim of this study was to explore the characteristics of specialists who provide ongoing outreach services, and to determine whether the nature of their service patterns contributed to ongoing service delivery.

\section{Methods}

Our study was based on a large national longitudinal survey of Australian doctors, the Medicine in Australia: Balancing Employment and Life (MABEL) study (mabel.org. au). The MABEL study commenced in 2008 by inviting all Australian doctors listed on the Australasian Medical Publishing Company directory (AMPCo Direct), the most comprehensive listing of medical practitioners in Australia at the time, to complete a print or online copy of a survey between June and November 2008. Doctors who responded were re-surveyed on an annual basis, between June and November each year, and doctors who were new to the AMPCo database (returning to the workforce or new graduates) were also surveyed. The participants were broadly representative of Australian doctors in general. ${ }^{11,12}$

\section{Study cohort}

We included specialist doctors who had completed advanced training to gain accreditation from a specialist medical college, who were working clinically, and who, when they first completed the survey in 2008 or 2009, had indicated that they had travelled to provide services in other 
geographic locations and had reported at least one rural location to which they had travelled (up to three could be listed). Locations were geocoded using the Australian Standard Geographical Classification - Remoteness Areas categories. ${ }^{13}$ Specialists not reporting a residential location (12 doctors) or a specific location that they had visited (35 doctors) were excluded from the study.

\section{Outcomes}

The series of annual surveys allowed us to observe whether specialists continued to travel to provide services to rural locations. Ongoing outreach was defined as providing outreach service to the same rural or remote town for at least a 3-year period (from 2008 or 2009, up to 2011). Ongoing outreach service delivery was assumed when data were missing if the specialist had provided outreach to the same town over at least two time points spanning at least a 3-year period, and in the interim year, (1) they did not respond to the survey, or (2) they continued to work clinically, with no indication that they had ceased travelling or had travelled to different communities.

The alternative outcome, ad hoc outreach, included specialists who responded to the survey over at least two time points, but who provided rural outreach service to the same community for less than 3 years, or ongoing outreach service was interrupted by a year of non-clinical work, not travelling, or visiting other towns.

\section{Variables}

Predictive variables were assessed when the specialist first completed the survey (2008 or 2009).

Age was categorised to reflect career stages: early career, < 45 years; midcareer, 45-64 years; and nearretirement, $\geq 65$ years.

The definition of practice sector was based on weekly hours worked in public hospitals, private hospitals, private consulting rooms, or "other" (aged care, education and other). Three categories were applied: "public sector" (public hospital only), "private sector" (private consultation rooms and/or private hospital, not public hospitals) and "mixed sector" (both public sector and "private sector). "Mixed sector" was further disaggregated to "mainly public" if the specialist spent more than the median hours (equivalent to more than $31 \%$ of their total work time) in a public hospital, or "mainly private". Specialists who reported most of their work hours in the "other" setting and less than 10 hours' work in public or private sectors or both public/private (if a mixed sector specialist) were excluded from this study.

The main specialty was self-selected from a list of 48 accredited specialties.

Four service patterns were defined according to the specialist's residential location (metropolitan or rural) and service destination (inner regional or outer regional/remote). The most remote service pattern was used if more than one rural location was visited.

Locations were approximated using town centroids, and straight-line distances (in kilometres) were calculated between the residential and outreach location. Distance was categorised as "local" $(<300 \mathrm{~km})$ or "distant" ( $\geq 300 \mathrm{~km})$, reflecting the probability that the specialist drove to the location. The most distant service was used if more than one rural location was visited.

Town size was categorised into four groups that were relatively homogenous according to professional and non-professional indicators: $<5,000$; 5000-15 000; 15 001-50 000; > 50000 people. ${ }^{14}$ The most remote town visited was applied if more than one rural town was visited.

The number of rural locations visited was re-coded as 1 or $2-3$.

\section{Analysis}

Data were analysed using Stata version 11.2 (StataCorp). First, bivariate associations of four covariates (age, sex, residential location and practice sector) were tested by logistic regression, odds ratios (ORs) and 95\% confidence intervals (CIs) to explore the characteristics of specialists who provided ongoing outreach.
Interactions were tested in the adjusted model using the Wald test. A single multiple logistic regression model included all these covariates.

A second, separate logistic regression tested the association between specialist type and ongoing outreach, expressed as ORs and 95\% CIs. Deviation contrasts compared each category of specialist type with the grand mean.

Finally, the association between the specialist's service patterns and ongoing outreach was tested by bivariate associations (ORs and 95\% CIs) for the remoteness of outreach service provision from metropolitan or rural locations, distance travelled, town size and number of rural locations visited.

The study was part of a research program with ethics approval from the University of Melbourne (Ref. 0709559) and Monash University (Ref. CF07/1102 - 2007000291).

\section{Results}

A total of 4596 specialists $(22.3 \%$ of those invited) completed the MABEL survey in 2008, and 348 specialists new to AMPCo (44.1\%) responded in 2009. After exclusions, the cohort providing rural outreach services included 953 specialists (893 in 2008, 60 in 2009). Of these, 105 (92 in 2008, 13 in 2009) did not respond to subsequent surveys or were not working clinically after entry to the survey. No attrition bias based on age $(P=0.30)$ or sex $(P=0.08)$ was detected.

We compared the characteristics of the final cohort of 848 specialists with those of the medical specialist workforce in Australia, and found that they were similar with respect to age, hours worked and specialist group (Box 1). The exception was that the proportion of older and rural doctors in the study cohort was approximately double that for the national specialist workforce; rural-based male specialists are more likely to participate in outreach work. ${ }^{4}$

\section{Specialist characteristics}

A total of 440 of 848 specialists (51.9\%) provided regular outreach to 
1 Characteristics of medical specialists providing rural outreach services, compared with those of the general Australian medical specialist workforce

\begin{tabular}{|c|c|c|c|c|}
\hline & \multicolumn{2}{|c|}{$\begin{array}{l}\text { Specialist doctors providing } \\
\text { rural outreach }(n=848)\end{array}$} & \multicolumn{2}{|c|}{$\begin{array}{c}\text { Australian specialist } \\
\text { workforce }(n=24290) *\end{array}$} \\
\hline & Male & Female & Male & Female \\
\hline Number (\% of group) & $656(77.4 \%)$ & $192(22.6 \%)$ & $18132(74.6 \%)$ & $6158(23.4 \%)$ \\
\hline \multicolumn{5}{|l|}{ Age } \\
\hline$<45$ years & $171(20.2 \%)$ & $76(9.0 \%)$ & $6284(25.9 \%)$ & $3334(13.7 \%)$ \\
\hline 45-64 years & 331 (39.0\%) & $103(12.1 \%)$ & 9596 (39.5\%) & $2569(10.6 \%)$ \\
\hline$\geq 65$ years & $154(18.2 \%)$ & $13(1.5 \%)$ & $2252(9.3 \%)$ & $255(1.0 \%)$ \\
\hline Mean age, years & 51.4 & 46.8 & 50.6 & 45.2 \\
\hline \multicolumn{5}{|l|}{ Location (main place of work) } \\
\hline Metropolitan & $423(49.9 \%)$ & $141(16.6 \%)$ & $13340(68.1 \%)$ & $3646(18.6 \%)$ \\
\hline Rural & $231(27.2 \%)$ & $49(5.8 \%)$ & $2203(11.3 \%)$ & $389(2.0 \%)$ \\
\hline \multicolumn{5}{|l|}{ Specialist group } \\
\hline Internal medicine & $218(25.7 \%)$ & $68(8.0 \%)$ & $4968(20.5 \%)$ & $1743(7.2 \%)$ \\
\hline Pathology & $20(2.4 \%)$ & $8(0.9 \%)$ & $707(2.9 \%)$ & $430(1.8 \%)$ \\
\hline Surgery & $116(13.7 \%)$ & $13(1.5 \%)$ & $4298(17.7 \%)$ & $500(2.1 \%)$ \\
\hline Other specialists & $299(35.3 \%)$ & $102(12.0 \%)$ & 8159 (33.6\%) & $3484(14.3 \%)$ \\
\hline Mean hours worked per week & 48.5 & 42.2 & 45.9 & 37.3 \\
\hline
\end{tabular}

There were four missing observations for specialist group and location (main place of work) for the outreach group, and one was missing for the Australian specialist workforce specialist group. * Data on the Australian specialist workforce were obtained from the Australian Medical Labour Force Survey, 2009, ${ }^{19}$ except the data on location (main place of work), which were obtained from the 2008 Australian Medical Directory dataset $(n=19578)$

the same community. The data in Box 2 show that ongoing outreach was associated with being male, midcareer and working in mixed but mainly private practice. Working in private-only practice was associated with lower levels of regular outreach service. Metropolitan and ruralbased specialists were equally likely to provide ongoing outreach service. There was no evidence of interaction in the multivariate analysis.

\section{Specialist type}

General surgeons $(30 / 40,75.0 \% ; P=$ $0.005)$ and otolaryngologists $(14 / 18$, $77.8 \% ; P=0.035)$ were more likely to provide regular outreach service, whereas laboratory specialists (15/ $45,33.3 \% ; P=0.01)$, anaesthetists $(22 / 65,33.9 \%$; $P=0.003)$ and emergency physicians $(6 / 25,24.0 \%, P=$ $0.005)$ were less likely. A range of other specialist types also provided a higher than average rate of ongoing outreach service, such as cardiologists $(14 / 19,73.7 \%)$, general physicians $(18 / 29,62.1 \%)$ and paediatricians $(37 / 66,56.1 \%)$, but these was not significantly different from the overall mean.

\section{Service patterns}

Box 3 shows that visiting more towns and visiting smaller towns $(<5000$ people) was associated with ongoing outreach service, but travel distance and visiting remote locations had no effect.

A sensitivity analysis confirmed that the assumptions for missing data were reasonable. Restricting the ongoing group to specialists for whom no assumption was made $(n=364)$ did not affect the results.

\section{Discussion}

Around half of all medical specialists providing rural outreach service in our study provided it to the same town on an ongoing basis. This suggests that the stability of rural outreach services could be improved. The characteristics of specialists, including their career stage, practice conditions, specialty type and aspects of their service patterns, influence the ongoing provision of outreach services.

\section{Career stability}

Male specialists at a more stable career stage were more likely to provide ongoing rural outreach services. Early career specialists could be restricted by the amount of time needed to develop their main practice or to fulfil hospital-based roles. One way to address their lower rate of regular outreach provision may be to structure outreach services to complement their commitments at their main practice. Team-based rotational arrangements require less time commitment by individuals, and including telehealth in the service platform can also reduce the number of visits needed. The attitude of employers to the participation of staff in outreach work also needs further investigation.

Specialists nearing retirement may not consider rural outreach work as part of their retirement work plan. However, it is possible that succession planning could provide a 
2 Univariate and multivariate analysis of association between specialist characteristics and ongoing rural outreach services $(n=848)$

\begin{tabular}{|c|c|c|c|c|c|}
\hline \multirow[b]{2}{*}{ Covariates } & \multirow{2}{*}{$\begin{array}{l}\text { Number reporting } \\
\text { continuity of outreach* }\end{array}$} & \multicolumn{2}{|c|}{ Univariate analysis } & \multicolumn{2}{|c|}{ Multivariate analysis } \\
\hline & & OR $(95 \% \mathrm{Cl})$ & $P$ & OR $(95 \% \mathrm{Cl})$ & $P$ \\
\hline Total & $440(51.9 \%)$ & & & & \\
\hline \multicolumn{6}{|l|}{ Sex } \\
\hline Female & 79 (41.2\%) & 1 & & 1 & \\
\hline Male & $361(55.0 \%)$ & $1.75(1.26-2.43)$ & 0.001 & $1.82(1.28-2.60)$ & 0.001 \\
\hline \multicolumn{6}{|l|}{ Age } \\
\hline$<45$ years & 115 (46.8\%) & 1 & & 1 & \\
\hline 45-64 years & $288(55.0 \%)$ & $1.39(1.02-1.88)$ & 0.03 & $1.44(1.04-1.99)$ & 0.029 \\
\hline$\geq 65$ years & $36(46.8 \%)$ & $1.00(0.60-1.67)$ & 0.99 & $0.99(0.57-1.74)$ & 0.99 \\
\hline \multicolumn{6}{|l|}{ Location of residence } \\
\hline Metropolitan & $300(52.5 \%)$ & 1 & & 1 & \\
\hline Rural & $140(50.7 \%)$ & $0.94(0.70-1.25)$ & 0.65 & $0.81(0.60-1.11)$ & 0.19 \\
\hline \multicolumn{6}{|l|}{ Practice sector } \\
\hline Public only & $120(49.2 \%)$ & 1 & & 1 & \\
\hline Mixed, mainly public & $114(50.7 \%)$ & $1.06(0.74-1.52)$ & 0.75 & $0.95(0.66-1.38)$ & 0.80 \\
\hline Mixed, mainly private & 145 (64.7\%) & $1.90(1.31-2.75)$ & 0.001 & $1.73(1.18-2.53)$ & 0.005 \\
\hline Private only & $42(36.5 \%)$ & $0.58(0.37-0.92)$ & 0.02 & $0.51(0.32-0.82)$ & 0.006 \\
\hline
\end{tabular}

$\mathrm{OR}=$ odds ratio. The number of respondents included in the final model was reduced to 807 : there was one missing observation for age, and 40 observations for weekly hours worked in different settings either missing or involving work in "other" sectors. * Percentages are based on corresponding figures for specialist doctors providing rural outreach in Box 1 .

structure for late career specialists to maintain some involvement with a reduced workload.

Previous research found that women were less likely to participate in rural outreach work, ${ }^{4}$ and our study found that they are also less likely to provide ongoing outreach services. The influence of sex on outreach workforce dynamics requires specific investigation.

\section{Conditions at the main practice}

Specialists working in the public and mixed, mainly public sectors in their normal practice provided similar rates of ongoing rural outreach services. Despite the potential security of salaried remuneration for outreach work, the workload of public sector employment and the financial constraints of the public system may restrict regular participation in outreach services.

Specialists working in mixed practice with a higher component of private work may have a greater sense of ownership and enthusiasm, considered important for ongoing outreach service delivery. ${ }^{6}$ However, there appears to be a tipping point: working in a fully private model reduced the likelihood of ongoing outreach services. We speculate that privateonly specialists are hindered by the costs and the demands that ongoing outreach work can place on their normal practice. ${ }^{7}$ Financial subsidies for the costs of travel and travel time may help facilitate ongoing rural outreach by specialists working privately. Australia's RHOF policy plays an important role supporting this. However, only some specialist types and a restricted number of doctors can gain subsidies through this fund, and other long-term financial incentives may be required to encourage ongoing outreach practice by private-only specialists.

\section{Specialist type}

To some extent, generalist specialists were more likely to provide ongoing outreach services. But at the other end of the spectrum, otolaryngologists, who are procedurally based and have high equipment demands, were also likely to provide ongoing service. This might be driven by the demographic and disease profiles of different rural communities. Further, it could be enabled by specialists widening their normal scope of practice during outreach work. ${ }^{15}$ Meanwhile, the RHOF, which targets sustained outreach in chronic diseases, and in maternal and child, ear and eye, and mental health, ${ }^{16,17}$ may need to be reinforced by other approaches targeting specialists working in priority areas of care, including intersite staff sharing, and hub-andspoke models from major public hospitals.

\section{Location and nature of service patterns}

The specialist's location did not influence the rate of ongoing outreach services. Mobilising specialists from metropolitan areas, where $85 \%$ of specialists live, could contribute to sustained service access in rural and remote locations. Although the distance the specialist travelled made no difference, it is still possible that the time spent travelling, which more closely determines any loss of 
3 Univariate analysis of association between patterns of service and ongoing rural outreach services $(n=848)$

\begin{tabular}{|c|c|c|c|}
\hline Covariates & $\begin{array}{c}\text { Number reporting } \\
\text { continuity } \\
\text { of outreach }\end{array}$ & $\begin{array}{l}\text { Univariate } \\
\text { analysis: } \\
\text { OR }(95 \% \mathrm{Cl})\end{array}$ & $P$ \\
\hline \multicolumn{4}{|l|}{ Remoteness of service } \\
\hline Metropolitan to inner regional & $172(50.7 \%)$ & 1 & \\
\hline Rural to inner regional & $60(43.8 \%)$ & $0.76(0.51-1.13)$ & 0.17 \\
\hline $\begin{array}{l}\text { Metropolitan to outer } \\
\text { regional/remote }\end{array}$ & $128(54.9 \%)$ & $1.18(0.85-1.65)$ & 0.32 \\
\hline Rural to outer regional/remote & $80(57.6 \%)$ & $1.32(0.88-1.96)$ & 0.18 \\
\hline \multicolumn{4}{|l|}{ Distance travelled } \\
\hline Local $(<300$ km) & $282(52.8 \%)$ & 1 & \\
\hline Distant ( $\geq 300$ km) & $158(50.3 \%)$ & $0.91(0.68-1.20)$ & 0.48 \\
\hline \multicolumn{4}{|l|}{ Size of town } \\
\hline$>50000$ & $55(46.2 \%)$ & 1 & \\
\hline $15001-50000$ & $167(48.1 \%)$ & $1.08(0.71-1.64)$ & 0.72 \\
\hline 5000-15000 & $97(51.9 \%)$ & $1.25(0.79-1.99)$ & 0.34 \\
\hline$<5000$ & $121(62.1 \%)$ & $1.90(1.20-3.02)$ & 0.006 \\
\hline \multicolumn{4}{|l|}{ Number of rural locations visited } \\
\hline 1 & $247(48.1 \%)$ & 1 & \\
\hline $2-3$ & $193(57.8 \%)$ & $1.48(1.12-1.95)$ & 0.006 \\
\hline
\end{tabular}

$\mathrm{OR}=$ odds ratio.

income, may influence choices about ongoing outreach services.

Outreach services delivered to smaller towns are likely to be structured differently and driven by different personal motivations to outreach services to larger towns, but this remains to be investigated. Smaller towns are less likely to have any resident specialist services. We propose that the nature of planning for outreach services in larger towns is worth exploring, to identify factors that could increase service stability.

This research did not study other parameters of sustainable outreach, such as the regularity of visiting, the quality, relevance and responsiveness of clinical and professional support, and the availability of a succession plan. Further, a range of factors with the potential to affect service maintenance, such as shortterm contracting ${ }^{6,7}$ and inadequate or inflexible funding, ${ }^{6,18}$ remain to be investigated.

Ongoing outreach was defined in our study on a conservative basis, being limited doctors to visiting the same town, whereas some specialists visited more than one rural location on a regular basis, while others visited different nearby towns. Rotational or team-rostered outreach was also not considered. Self-administered survey methods mean there is some potential for under-reporting of participation. There was also a small degree of survey dropout and movement in and out of the annual survey. Finally, we were limited to analysing 4 years' data.

A small proportion of specialists in our cohort moved from a metropolitan to a rural location or vice versa during the study. However, moving location should not, theoretically, alter the ability to continue visiting a town. Further, we did not account for changes to practice sector, because the hours worked in different settings are very sensitive to change over time; we could not be sure whether any change reflected a definite change in practice.

In summary, a range of strategies is needed to promote more stable rural outreach services, taking into account the individual specialist's career stage, practice conditions and specialty. Financial incentives are likely to increase ongoing outreach services only by specialists working privately. Our research indicates that outreach services to smaller communities are more stable.

Acknowledgements: This publication used data from the MABEL longitudinal survey of doctors conducted by the University of Melbourne and Monash University (the MABEL research team). Funding for MABEL comes from the National Health and Medical Research Council (Health Services Research Grant: 2008-2011; and Centre for Research Excellence in Medical Workforce Dynamics: 2012-2016), with additional support from the Commonwealth Department of Health (in 2008) and Health Workforce Australia (in 2013). Belinda O'Sullivan is supported by an Australian Postgraduate Award.

Competing interests: No relevant disclosures.

(c) 2015 AMPCo Pty Ltd. Produced with Elsevier B.V. All rights reserved. 
1 Gruen RL, Bailie RS, Wang Z, et al. Specialist outreach to isolated and disadvantaged communities: a population-based study. Lancet 2006; 368: 130-138.

2 Simm PJ, Wong N, Fraser L, et al. Geography does not limit optimal diabetes care: use of a tertiary centre model of care in an outreach service for type 1 diabetes mellitus. J Paediatr Child Health 2014; 50: 471-475.

3 Thomas CL, O'Rourke PK, Wainwright CE. Clinical outcomes of Queensland children with cystic fibrosis: a comparison between tertiary centre and outreach services. Med J Aust 2008; 188: 135-139. https://www. mja.com.au/journal/2008/188/3/ clinical-outcomes-queenslandchildren-cystic-fibrosis-comparisonbetween-tertiary

4 O'Sullivan B, Joyce C, McGrail M. Rural outreach by specialist doctors in Australia: a national cross-sectional study of supply and distribution. Hum Resour Health 2014; 12: 1-10.

5 Gruen RL, Weeramanthri TS, Bailie RS. Outreach and improved access to specialist services for indigenous people in remote Australia: the requirements for sustainability. $J$ Epidemiol Commun Health 2002; 56: 517-521.

6 Gadiel D, Ridoutt L, Bune A, et al. Evaluation of outreach models of medical specialist service delivery. Sydney: Human Capital Alliance International, 2004. http://www. humancapitalalliance.com.au/ downloads/DH28\%20Specialist\% 20outreach\%20model\%20evaluation. PDF (accessed Jul 2015).
7 Cord-Udy N. Remote area indigenous psychiatry: not your usual day at the office. Australas Psychiatry 2006; 14: 295-299.

8 House of Representatives Standing Committee on Regional Australia. Cancer of the bush or salvation for our cities? Fly-in, fly-out and drive-in, drive-out workforce practices in regional Australia. Canberra: Parliament of the Commonwealth of Australia, 2013. http://www.aph.gov. au/parliamentary_business/ committees/house_of_representatives committees? $\mathrm{ur}=\mathrm{ra} / \mathrm{fifodid} /$ /report. htm (accessed Jul 2015).

9 Alexander C, Fraser J. Medical specialists servicing the New England Health Area of New South Wales. Aust J Rural Health 2001; 9: 34-37.

10 O'Sullivan BG, Joyce CM, McGrail MR. Adoption, implementation and prioritization of specialist outreach policy in Australia: a national perspective. Bull World Health Organ 2014; 92: 512-519.

11 Joyce C, Scott A, Jeon S-H, et al. The "Medicine in Australia: Balancing Employment and Life (MABEL)" longitudinal survey - protocol and baseline data for a prospective cohort study of Australian doctors' workforce participation. BMC Health Serv Res 2010; 10: 1-10.

12 Yan W, Cheng TC, Scott A, et al. Medicine in Australia: Balancing Employment and Life (MABEL). Aust Econ Rev 2011; 44: 102-112.

13 Australian Bureau of Statistics. The Australian Statistical Geographical Classification (ASGC) Remoteness Structure. Canberra: ABS, 2006. http://www.abs.gov.au/websitedbs/ d3310114.nsf/home/remoteness+ structure\#Anchor2 (accessed May 2015).

14 Humphreys JS, McGrail MR, Joyce CM, et al. Who should receive recruitment and retention incentives? Improved targeting of rural doctors using medical workforce data. Aust J Rural Health 2012; 20: 3-10.

15 Foy A, Tierney A. Internal medicine in the bush: a clinical audit of a rural and remote outreach programme. Intern Med J 2014; 44: 369-374.

16 Department of Health and Ageing. Healthy ears - better hearing, better listening service delivery standards. Canberra: DoHA, 2013. http://www. ruralhealthwest.com.au/docs/outreachin-the-outback-docs/healthy-earsservice-delivery-standards.pdf? sfvrsn=2 (accessed May 2015).

17 Department of Health and Ageing. Rural Health Outreach Fund - Service delivery standards: rural and regional health Australia. Canberra: DoHA, 2012. http://www.ruralhealthaustralia.gov. au/internet/rha/publishing.nsf/ Content/RHOF-service-deliverystandards (accessed May 2015).

18 Turner AW, Mulholland W, Taylor HR. Funding models for outreach ophthalmology services. Clin Experiment Ophthalmol 2011; 39: 350-357.

19 Australian Institute of Health and Welfare. Medical labour force survey. Canberra: AlHW, 2009. http://www. aihw.gov.au/publication-detail/?id=1 0737419680\&tab=3 (accessed May 2015). 